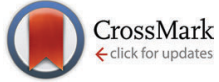

Cite this: Phys. Chem. Chem. Phys., 2015, 17, 15508

Received 21st January 2015 Accepted 20th March 2015

DOI: $10.1039 / c 5 c p 00375$

www.rsc.org/pccp

\title{
Bioinspired nanoreactors for the biomineralisation of metallic-based nanoparticles for nanomedicine
}

\author{
Jennifer Bain and Sarah S Staniland*
}

\begin{abstract}
This review explores the synthesis of inorganic metallic-based nanoparticles (MBNPs) (metals, alloys, metal oxides) using biological and biologically inspired nanoreactors for precipitation/crystallisation. Such nanoparticles exhibit a range of nanoscale properties such as surface plasmon resonance (nobel metals e.g. Au), fluorescence (semiconductor quantum dots e.g. CdSe) and nanomagnetism (magnetic alloys e.g. CoPt and iron oxides e.g. magnetite), which are currently the subject of intensive research for their applicability in diagnostic and therapeutic nanomedicine. For such applications, MBNPs are required to be biocompatible, of a precise size and shape for a consistent signal or output and be easily modified with biomolecules for applications. Ideally the MBNPs would be obtained via an environmentallyfriendly synthetic route. A biological or biologically inspired nanoreactor synthesis of MBNPs is shown to address these issues. Biological nanoreactors for crystallizing MBNPs within cells (magnetosomes), protein cages (ferritin) and virus capsids (cowpea chlorotic mottle, cowpea mosaic and tobacco mosaic viruses), are discussed along with how these have been modified for applications and for the next generation of new materials. Biomimetic liposome, polymersome and even designed self-assembled proteinosome nanoreactors are also reviewed for MBNP crystallisation and further modification for applications. With the advent of synthetic biology, the research and understanding in this field is growing, with the goal of realising nanoreactor synthesis of MBNPs for biomedical applications within our grasp in the near future.
\end{abstract}

\section{Introduction}

\section{Applications of metallic-based nanoparticles (MBNPs)}

The field of metallic-based (metals, alloys and metal oxides) nanoparticles (MBNPs) is becoming ever more prominent due to the emergence of numerous applications across a wide variety of disciplines and fields. Perhaps the most prominent application, outlined in many recent nanoparticle and nanoreactor publications, is in the field of biomedicine. MBNPs display a range of useful nanoproperty characteristics; namely nanomagnetism for magnetic nanoparticles (MNPs), fluorescence for semiconductor quantum dots (QDs) and increased photon scattering and absorbance due to surface plasmon resonance (SPR) for nanoparticles (NPs) of nobel metals. These characteristics are extremely applicable in the field of biomedicine. For example the incorporation of magnetism into a NP designed for drug delivery allows this to be magnetically directed to the site, making it a targeted therapy, which would then require lower dosage and reduce toxicity to the rest of the body. Furthermore, such magnetic character can open up the possibility of further application as a diagnostic agent. MNPs are excellent diagnostic

Department of Chemistry, University of Sheffield, Brook Hill, Sheffield S3 7HF, UK. E-mail: s.s.staniland@sheffield.ac.uk tools in magnetic resonance imaging (MRI), as the interaction of their local field with the MRI magnetic field can significantly enhance contrast in vivo. This is achieved by the MNP having a shorter $\mathrm{T}_{2}$ (spin-spin) relaxation time relative to the surrounding tissue, hence improving contrast between MNP tagged and untagged cells. ${ }^{1,2}$ The effect on relaxation time can be controlled by control of the MNP size, which in turn also controls magnetic properties, as more magnetic material will have increased $\mathrm{T}_{2}$ relaxation rates and thus provide greater contrast. ${ }^{2}$ Similarly, magnetic particle imaging (MPI) maps the position in vivo of magnetic tracer particles. ${ }^{3}$ Using this technique it is possible to image these tracer particles with an acquisition time of $<0.1 \mathrm{~s}^{3}$ Although as yet un-optimised, MPI is expected to be a more cost effective alternative to current techniques such as MRI. ${ }^{3}$ MNPs can also be utilised for magnetic hyperthermia therapy which relies on an alternating magnetic field, which switches the individual spins (for larger single-domain MNPs) or physically flips the whole particle (for smaller superparamagnetic MNPs). This internal or external magnetic switching can induce heating which is transferred to the surrounding area, damaging or killing the diseased tissue. ${ }^{4-6}$ There are thus two different mechanisms for heating that are highly dependent on the magnetic nanoparticle size, but within each regime the heating is dependent on the magnetic saturation and coercivity of the 
MNPs as well as the alternating field frequency. In the case of superparamagnetic NP which can physically rotate in the field, the interaction of the MNP's with the surrounding tissue can induce heating as the result of friction. Surface plasmon resonance (SPR) is exhibited by nobel metal NPs and can have similar potential in medical diagnostics and therapeutics. Although most commonly observed in gold or silver NPs any metal or alloy which has a large negative real dielectric constant can be tuned to display an SPR. The SPR effect is induced by irradiation with light. This irradiation causes conduction electrons driven by the electric field to oscillate at a specific resonant frequency which is dependent on the particle composition, size and structure. Similarly to MNPs, NPs with SPR characteristics can be used in heat dissipation, due to the conversion of photon energy to phonon (lattice vibrational) energy when exposed to light at a specific wavelength. The heat created by this conversion can then dissipate into surrounding tissues in vivo in a process analogous to magnetic hyperthermia treatment. Furthermore by controlling the nanoparticle structure and shape (i.e. rod, shell, particle) this plasmonic effect can be tuned to be in the visible or near infrared region, making a valuable biosensor for binding kinetics or to enhance contrast in techniques such as optical coherence tomography, used in non-invasive biopsies. ${ }^{7,8}$ Size tuneable photoluminesence is also achievable with quantum dots (QDs). QDs are semiconductor NPs whose excitations are in three spatial dimensions. This unique characteristic offers properties which again have the potential to vastly improve biosensing and imaging in medicine. QDs have an extremely broad absorption and narrow emission band which is tuneable with QD size. This means they offer superior fluorescence, lifetime and resistance to bleaching when compared to more conventional fluorescent biomarkers such as green fluorescent protein, and have proven to be successfully funtionalised, by conjugation to biological moieties. QDs are perceived to be inherently toxic due to their composition, which generally includes heavy metals such as cadmium. However work is ongoing to move away from these issues by investigating less toxic materials for QDs and using new synthesis methods discussed in this review to lessen toxic effects so their bioimaging potential can be realised. ${ }^{9,10}$ All of these applications particularly those in vivo demand strict control with respect to the particle properties and thus the composition, size and shape, but in many cases this can be hard to achieve using conventional synthetic routes, often involving extreme reaction conditions and toxic reagents. Much of the work to develop precise MBNPs is being carried out with the ultimate goal of realisation in medicine applications. ${ }^{6,11}$ Nanocomponents hold potential for improvement of drug delivery techniques, ${ }^{12-14}$ hyperthermic treatment of tumours, ${ }^{5,6}$ creation of diagnostic toolkits; e.g. MRI contrast agents ${ }^{6,15,16}$ and simultaneous diagnostic and therapeutic nanomaterials; termed theranostics. ${ }^{15,17-19}$ This drive for use of MBNPs in biomedical applications dictates a requirement for an extremely high level of consistency and reproducibility during MBNP synthesis with respect to the NP properties discussed above, not only from particle to particle but also from batch to batch. The need for tight constraint is a consequence of utilising nanoscale physical properties for in vivo application. Ideally, employing a synthetic route that operates at the nanoscale will offer higher levels of nanoscale precision over the process.

\section{Synthesis of metallic-based nanoparticles (MBNPs)}

The mineralisation of MBNPs occurs when insoluble NPs are precipitated out of solution from soluble precursors. This is achieved when metal salts are oxidised (in the case of metal oxides) or reduced (in the case on metals, alloys and semiconductors). Controlling this process can be challenging due to factors such as multiple intermediate phases, unwanted oxidation, side reactions and by-products that can all contaminate the final product. Furthermore, crystallisation (nucleation and crystal growth) is governed by a complex interplay of both thermodynamic and kinetic factors that render the process and thus the resulting particle size and morphology of the population, particularly sensitive to reaction conditions. The best means of controlling the particle uniformity with respect to size and shape is to ensure simultaneous nucleation, via increased temperature and/or initiate an instant burst of nucleation by injection of a precursor into the hot reaction solution (hot injection). Such methods have been used to synthesis a range of monodispersed QDs ${ }^{20}$ and magnetic nanoparticles (MNPs). ${ }^{21}$ However, such synthetic routes, involve high temperature, toxic precursors and organic solvents, they are economically unfavourable, labour intensively and environmentally costly, particularly in a climate striving for greener chemical synthetic routes. ${ }^{22}$ To demonstrate the variation of NP products with different synthetic methods, we will consider the mineralisation of the iron oxide magnetite. Magnetite is an inverse spinel crystal lattice that contains iron in both ferrous and ferric oxidation states. This balance of oxidation states can easily be tipped to favour a range of competing iron oxides produced by subtly changing the reaction conditions such as temperature, precursor oxidation states, ratio, anions present, atmosphere etc. This can affect changes in the particle properties particularly its magnetism, but also the size and shape of the resulting crystal which may be critical to certain applications. There are a number magnetite precipitation routes, each having their advantages and disadvantages as well as different end crystal morphology. ${ }^{23}$ For example room temperature co-precipitation methods are green, but produce small ill-defined particles over a very large size distribution and are liable to contain contaminant iron oxides. Further to this, a precipitation method of heating a ferrous iron precursor produces larger more uniformed octahedral particles but the size distribution is still relatively broad. Contrarily, there are numerous high temperature methods which produce particles of defined size and shape but involve harsher chemical and physical conditions. ${ }^{21,23-25}$ Similar challenges can also be seen in the synthesis of the other MBNPs, such as QDs ${ }^{10}$ and gadolinium MRI contrast agents. ${ }^{26}$

Conducting a chemical reaction within a confined space or compartment (termed nanoreactors) can alleviate such issues, especially if we consider biological nanoreactors.

\section{Compartmentalisation in nature}

Synthetic biology and biological nanoreactors. Compartmentalisation is a natural phenomenon observed throughout nature, with the nanoreactor being fundamental to biology. The most obvious example of a compartmentalised nanoreactor is 
the cell or organelle, a term first coined by Mobius, which directly refers to the sub-structures and membrane bound biological compartments that have been studied for centuries. ${ }^{27}$ For a cell, reactions within segregated compartments are fundamental to its function. The cell is perfectly designed specifically to orchestrate a series of cascade reactions, and so is able to introduce specific reagents at precise times, with optimum efficiency. ${ }^{28}$ The multiple compartments created by a cell, allow for influx and efflux of cargo across membranes into the cells compartments. This drives multiple reactions taking place simultaneously keeping a cell operative and essentially "alive". This process is designed so perfectly that many studies on the use of both naturally occurring and synthetic nanoreactors take their inspiration from the processes observed in cells. ${ }^{29-31}$ The understanding of these processes are now being exploited by researchers in countless disciplines, and as a result we have seen the emergence of both biomimetic and bioinspired research. This relatively new, rapidly growing field of research exploits aspects of biology by mimicking and engineering them for novel utilisation; under the umbrella term "synthetic biology".

Broadly speaking there are two branches to the field of synthetic biology: top-down and bottom-up. Top-down is an extension of biotechnology into cellular metabolic engineering, which has sought to explain biological observations from a systems perspective in order to design and engineer new processes within a living organism. This methodology has distinct advantages: the most compelling being that adaption of a living organism intrinsically offers the benefits of a living system such as growth and regeneration. Furthermore, the products are intrinsically biocompatible (an essential property for biomedical application), while the research also serves to further our understanding of the mechanisms of these systems and processes in vivo. However, there are limitations when one considers the extent to which a process can deviate from the natural. i.e. the process must be within the boundaries of what is possible within a living cell.

By contrast, the bottom-up methodology has its roots in the fields of bionanoscience and protocells. It focuses on the individual building block components and using these and mimics thereof to design and build completely new artificial biological systems from first principles. Much of the work in the field is based around the design of entirely synthetic components such as vesicle compartments and incorporation of processes usually only observed in cells into these structures, summarised in the reviews by Vriezema and Dzieciol. ${ }^{28,30}$ The advantages to this methodology are that it allows for complete control over each element in the system and the creation of novel materials, far removed from natural products, which not only aids our understanding of biological processes ex vivo but also opens up opportunities for broader application of such systems. Here the key challenges are in biocompatibility of the products and scale-up of the processes.

For both disciplines, the engineering of complex systems is based on the principle of reuse and mimicry of components, tools and methodologies in a systematic way to achieve desired functionality of new (unnatural) systems. The flagship example of synthetic biology that defines what has been learnt from the top-down principle and subsequently uses the bottom up methodology to build a synthetic cell or protocell, which has been extensively explored in multiple other discussions. ${ }^{29,30,32,33}$ The field has been reinforced by pioneering research by those such as Venter et al., responsible for the synthetic bacterial cell; which has proved hugely advocatory for synthetic biology in the public domain. ${ }^{34}$

While much of the work in the field of synthetic biology is outside the scope of this review, parallels can be drawn between the emergence of synthetic biology and the biomimetic routes to mineralisation within biological and bioinspired nanoreactors discussed throughout this review.

Nanoreactors for biomineralisation of metallic-based nanoparticles. Performance of a precipitation reaction within a nanoreactor (nanoscale compartment) can prove highly beneficial for obtaining the specific properties that can only be gained at the nanoscale, where the demand for consistency is heightened. ${ }^{35}$ MBNP mineralisation within a biological or biologically inspired nanoreactor has several key benefits:

(1) Heterogeneous nucleation is aided by providing a surface, in this case the membrane of the nanoreactor, for metal ions to nucleate on. This means that the concentration of metal ions does not need to be at supersaturation levels for nucleation to commence. Furthermore the surface of the nanoreactor can be designed around the location of nucleation sites to promote specific crystal growth. ${ }^{36-38}$ Once crystal growth is underway, specifically designed active sites or proteins in the membrane can interact with the growing crystal to block growth on specific crystal faces, thus controlling the particle morphology. ${ }^{37}$

(2) The overall nanoreactor structure provides a perfect template for NP morphology. The nucleation and propagation steps of crystallization occurs within the confinement of the nanoreactor boundaries, leading to precise sized and morphologically monodisperse populations of particles. ${ }^{39}$ Furthermore and less obvious, biotemplating can be achieved on the exterior of the structure to form precise mineralised shell MBNPs, which will also be briefly reviewed.

(3) The compartment provides control over the form and availability of precursors and thus affects the reaction and resulting NPs produced. This is a particularly sensitive reaction parameter, with outcomes changing significantly even between different forms of compartmentalisation. ${ }^{28}$ Studies of crystal growth in confined volumes ${ }^{40}$ and substrates ${ }^{41}$ confirm this hypothesis. The crystallisation of calcium carbonate both in picolitre droplets and in an angular wedge showed that for a finite concentration, slower crystallisation rates and shorter precipitation time resulted in higher quality particles. These studies also show that removal of the confined environment can reduce mineral stability. This sentiment is echoed by intravesicular biomineralisation study which notes that cells can kinetically stabilise internal growth of minerals. ${ }^{42}$

(4) Taking a biomimetic approach to the crystallisation of MBNPs inherently requires greener environmental conditions, with reactions occurring under ambient conditions in aqueous medium. Bulk synthetic reactions performed under these conditions 
lead to poor particle composition, uniformity and quality, however formation within a biological nanoreactor results in high quality monodispersed NPs for the reasons outlined above, removing the need for harsh solvent or high temperatures.

(5) The biomineralisation of MBNPs in a nanoreactor leads to biocompatible materials that are ready for biomedical applications, without an express need for further processing. For example, precipitation of magnetite within the vesicle would make it responsive in a magnetic field, or compartmentalisation of QD synthesis removes toxicity and functionalises a vesicle for fluorescence detection. Additionally, if novel therapeutics and targets were required, the biocompatible nanoreactors can easily be further functionalized. Furthermore, as well as templating, the nanoreactors could be further functionalised by encapsulating different NPs for multimodal use. ${ }^{43}$

Therefore many groups, are working towards the development and improvement of nanoreactor design and biomineralisation reactions for in situ precipitation of MBNPs. This can be achieved by a number of different approaches. One uses a more top-down "biokleptic" approach by adapting nanoreactors found in nature, such as protein cages ${ }^{44,45}$ and viruses. ${ }^{46}$ Another uses cellular vesicles as bio-inspiration for the design and synthesis of artificial vesicle nanoreactors from the bottom-up. Vesicles can self-assemble from almost any amphiphilic material, by numerous routes ${ }^{47-50}$ and in certain cases assembly is possible from a non-amphiphilic starting material ${ }^{51}$ allowing for a wide variety of properties to be incorporated. Most commonly, vesicles are formed from lipid molecules (liposomes) or specifically designed amphiphilic polymers (polymersomes). Such building blocks can also be controlled to self-assemble into structures such as micelles or nanotubes. Vesicles are suitable nanoreactors for a wide variety of purposes, such as incorporation and functionality of membrane proteins, encapsulation of therapeutics for in vivo drug delivery and as analytical tools in a range of fields, which have been widely discussed in numerous other comprehensive reviews. ${ }^{17,48,49,52}$

Other reviews have outlined both the properties and potential application of both naturally occurring and synthetically engineered nanoreactors. ${ }^{28,53-55}$ The concept covered in this review is to use biological nanoreactors (cells, protein cages, viruses) or seek inspiration from nature to design biomimetic nanoreactors (liposomes, polymersomes) which can compartmentalise the biomineralisation of MBNPs that result in more precise particle sizes and morphology under milder reaction conditions. Such biocompatible vesicle material can then be further functionalised for a wide variety of biomedical application.

\section{The review}

\section{Biomineralisation in natural organisms}

Compartmentalised biomineralisation reactions occurs in numerous organisms ranging from humans to algae. ${ }^{56}$ Biomineralisation is the crystallisation or precipitation of an inorganic material within or around a cell or organism. ${ }^{57}$ There are two distinct types of biomineralisation, the first is "biologically induced mineralisation" in which the precipitation of a mineral is a by-product of a biochemical process. In these cases there is often little to no control over the mineral formed. The second type is "biologically controlled mineralisation" whereby the organism deliberately forms the mineral to fulfil a function (i.e. protective (shell), structural (skeleton), attack and defence (claws and teeth)). In this case the minerals are intricately designed with respect to requirements such as size, shape, toughness etc. Transmembrane metal ion transport proteins or morphological controlling proteins are commonly utilised to control crystallisation of the resulting particles with superior properties when compared to equivalent synthesised particles.

These mechanisms can be seen in the precipitation of a wide variety of minerals the vast expanse of which cannot be discussed thoroughly as part of this review. However some key examples include the biomineralisation of calcite, which highlights the controlled, complex and often beautiful architectures that can be achieved by nature. Such architectures can be seen in multiple species of mollusc and coral which biomineralise their hard outer shell; vital for protection. The coccolith is also an excellent example of this process; formed in intracellular vesicles and subsequently exorcised, these structures comprise individual biomineralised $\mathrm{CaCO}_{3}$ plates which then assemble into spheres (Fig. 1i). ${ }^{57-59}$ Coccoliths have provided a model system for the study of biomineralisation mechanisms and are indicative of the high levels of complexity that can be achieved if one adopts a bioinspired method. This sentiment is reflected in the lesser studied biomineralisation of silicates in diatom algae, again extensive and complex architectures are formed by the polymerisation of biogenic silica, similarly used as armour for the organism's survival. ${ }^{60}$ Understanding the mechanism by which these organisms biomineralise can inform new routes to biomimetic and bioinspired synthesis of novel and improved materials. ${ }^{61-63}$ Biomineralisation can vary in size from nanometres to metres (when one considers biomineralisation of bones in large animals). However, in the context of this review compartments for biomineralisation tend to fall in the range of $8 \mathrm{~nm}$ up to $2 \mu \mathrm{m}$ diameters, indicating nanoreactors can be utilised for the precipitation of monodisperse minerals over a range of sizes. ${ }^{28,35,64,65}$

Crystallisation of magnetite is perhaps one of the most common forms of metal oxide biomineralised materials found in nature. examples of this process are wide ranging, with biomagnetite being found everywhere from chiton teeth to the NPs within the brains of insects, birds and humans. ${ }^{56,66}$ Arguably the most intricate and well-studied example of magnetite biomineralisation is the formation of the magnetosome in magnetic bacteria (MTB). ${ }^{67}$

Magnetic bacteria. Extensive research has been carried out into the biomineralisation of magnetite MNPs within the membrane enclosed vesicles, termed magnetosomes, within specific strains of MTB (Fig. 1ii). ${ }^{67-73}$ The reason for magnetosome production is still a heavily debated point although many argue it is for magnetotaxis ${ }^{74,75}$ it has also been suggested it is for magneto-aerotaxis, ${ }^{76}$ respiration ${ }^{77}$ or detoxification. ${ }^{78}$ Since their unpublished discovery by Bellini in $1963^{79}$ and rediscovery 
(i)



(ii)

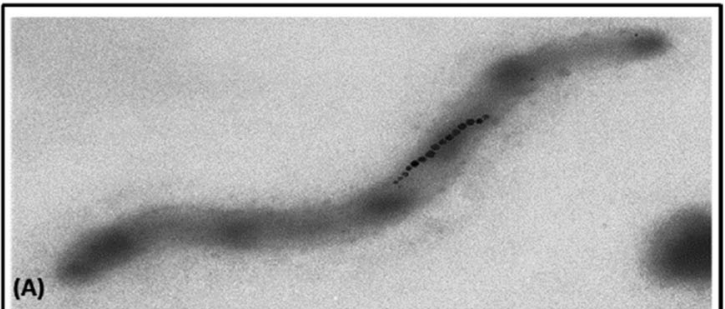

(A)



(iii)
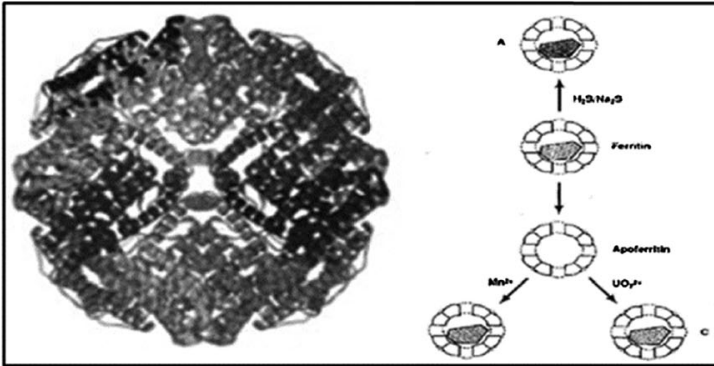

Fig. 1 Natural biomineralisation within organisms. Clockwise from left: (i) architectures observed in nature as the result of calcium carbonate biomineralisation in coccoliths. (Adapted with permission from Young et al. ${ }^{59}$ ); (ii) formation and biomineralisation of the magnetosome in magnetic bacteria. (A) Example of magnetospirillum magnetotacticum MS-1. (B) Schematic of formation of the magnetosome vesicle, recruitment of iron and morphological control exerted by bacterial proteins in (reproduced with permission from Arakaki et al. ${ }^{72}$ ). (C) The various particle morphologies observed in different species of magnetic bacteria (reproduced with permission from Schuler, FEMS Microbiology rev. 2008). (iii) Structure of iron storage protein ferritin and possible biomineralisation pathways of ferritin and apoferritin as suggested by Mann et al. (Reproduced with permission from Ueno et al. ${ }^{63}$ and Mann et al. ${ }^{97}$ )

by Blakemore in $1975^{67}$ multiple research groups have emerged dedicated to understanding the mechanism of biomineralisation of magnetosomes. It is widely accepted that the formation process is heavily biologically controlled. The proteins for this process are encoded by an area of the genome known as the "Magnetosome Island". ${ }^{70,80}$

Sufficient ferrous concentrations are only reached in MTB due to the compartmentalisation of the reaction within vesicles formed by invagination of the cytoplasmic membrane to form a liposome. ${ }^{69,81} \mathrm{~A}$ hypothesis confirmed by Stolz, ${ }^{82}$ with the discovery that magnetosomes are only present in cases where a sufficiently high ferrous ion sources are available. ${ }^{71}$ Lipidiomic and electron microscopy analyses show that the bacterial vesicles contain a suite of proteins specific to the magnetosome. ${ }^{69}$ Further studies such as gene knockout mutagenesis ${ }^{83,84}$ genomic studies $^{70}$ and proteomic studies ${ }^{85-87}$ are trying to understand the role of these proteins. Numerous reviews detail what is already known about the formation of the magnetosomes and their potential for application. ${ }^{27,70,72,75,88,89}$ However, briefly the mechanism is comprised of a number of steps. Initially the magnetosome nanoreactor recruits iron through transmembrane iron-transporter proteins, which also function as antiporters, as iron is recruited into the magnetosome core protons are pumped out, raising the $\mathrm{pH}$ of the internal magnetosome environment. The resulting $\mathrm{pH}$ increase within a supersaturated iron environment leads to the precipitation of a single magnetite nanocrystal within the magnetosome core. The formation of which is controlled with respect to size and shape by specific biomineralisation proteins (Fig. 1ii). If we can fully understand the formation of the magnetosome from first principles; from the formation of the vesicle, to the role of each protein involved and how they work in concert to form the resulting MNPs, we can use this knowledge to attempt the bottom-up creation of an artificial magnetosome and thus enable superior biomimetic biomineralisation within nanoreactors.

Until we can create a fully biomimetic magnetosome, work is ongoing to understand the extent to which bacterial magnetosomes can be modified and functionalised. ${ }^{88}$ Magnetosomes properties have proven to be superior in several applications when compared with synthetic analogues ${ }^{88}$ and there is a concerted effort to functionalise magnetosomes for a range of extensive applications, ${ }^{90-94}$ from targeted therapeutics, to DNA extraction, immunoassays and bio-sensing of toxic substances. The extensive list of possibilities outlined by Lang et al. ${ }^{88}$ and Matsunaga et al. ${ }^{90-94}$ demonstrates the potential of magnetosomes ex vivo in nanomedicine.

Despite their potential the anaerobic and slow growing nature of MTB makes cultures difficult to work with and yields are commonly low, making industrial scale-up economically impractical. Bacterial magnetosomes directly for application may not prove to be industrially scalable, but it is envisaged that we could harvest their potential by biomimetically recreating the system. 


\section{Biokleptic nanoreactors}

Biokleptic is a term that means to use a component directly from nature (as opposed to biomimetic, meaning mimicking a natural component). Nature produces a wide range of nano and microscale compartment structures that have the potential to act as nanoreactors. The advantage of using a compartment/ vesicle directly extracted from nature is to utilise the natural advantages of their self-assembly properties and capacity to be genetically modified. As such, in this section we will concentrate on the simplest self-assembly protein cages as nanoreactors for MBNP crystallisation, namely examples of cage-proteins, virus and capsids and finally the decoration of such structures with biomineralisation proteins to directly control crystallisation.

Ferritin (in vitro). Perhaps the most recognizable example of accumulation and biomineralisation in most organisms is the iron storage protein ferritin. The self-assembling cage protein ferritin, has been widely studied both in vivo and in vitro. Ferritin is a 24 subunit protein, capable of assembling into a protein cage sphere with an internal diameter of $8 \mathrm{~nm}$. (Fig. 1iii) In vivo this internal space is utilised in recruitment of iron, which is then stored in a non-toxic form; most commonly the iron oxide ferrihydrite. ${ }^{61}$ This process is essential in mammalian physiology for the production of heme, but ferritin is also found in almost all organisms, and is essential in the regulation of internal iron concentrations. There have been multiple studies into the properties and function of ferritin and it is poignant to note that the biomineralisation that occurs within ferritin is not concerned with the controlled formation of a precise material, but rather the composition of the mineral is superfluous as a by-product of iron-storage and as such ferrihydride is a disordered iron oxide of limited use. Despite this, ferritin is an ideal nanoreactor to investigate for the internal precipitation of various metallic minerals in vitro. (Fig. 1iii) Ferritin is a biocompatible extremely organised scaffold that can act as an excellent template for mineralisation and is aided by ion channels situated at the junctions of each subunit, to enable the transport of metal ions into its core. ${ }^{63}$ It has thus been used to template a range of nonferrous MBNPs synthesis such as Pd biocatalyst for size selective hydrogenation of olefins. ${ }^{63}$ To date ferritin has been utilised to template the synthesis of; manganese oxide NPs, ${ }^{95}$ cadmium sulphide QDs, ${ }^{96}$ both uranyl oxide ${ }^{97}$ and cobalt platinum NPs ${ }^{98}$ and the magnetic mineral magnetite, ${ }^{99}$ in addition to the storage of several multi-nuclear metal nanoclusters. ${ }^{100-103}$

Manipulation of the native ferritin protein structure has also been achieved. For example Shin et al. has shown how the internal diameter of the ferritin protein cage can be altered by control of the internal chemical composition. In a study involving the precipitation of $\mathrm{Au}-\mathrm{Ag}$ alloy NPs within the core of apoferritin it was possible to increase and decrease NP diameter by alteration of ratio of $\mathrm{Au}$ to $\mathrm{Ag} .{ }^{104}$ The group were able to gradually increase the alloy NP diameter by $0.7 \mathrm{~nm}$; from 5.6 to $6.3 \mathrm{~nm}$ by slow addition of $\mathrm{Ag}$. Mutation of the inner binding sites by the introduction or deletion of residues in the proteins core can dictate both the species and coordination of crystals biomineralised. This has been demonstrated in the case of Pd complex manipulation changing from a dinuclear to trinuclear complex by changing the Pd coordinating residue from a histidine to an alanine though mutagenesis. ${ }^{62}$

Protein cages and virus capsids. The exploitation of virus protein cages for mineralization of MBNP materials is an obvious expansion to the ferritin protein cage nanoreactors. This family of components is so extensive that these structures offer a vast range of pre-determined compartment sizes and even shapes ideal for successful compartmentalised biomineralisation reactions. Each biological template can be utilised in multiple ways using either the core of the cage or even the outer shell. Due to the way in which many virus protein cages assemble, it is also possible to use the spaces between subunits as either sizeselective mineralisation interfaces or to assist transport for internal mineral precipitation. Protein cages, such as those surrounding viruses are often thought to be superior to synthetic inorganic cages as their subunit structure is in orders of magnitude that could never be reached synthetically. Furthermore functionalities such as ion channels and other transmembrane transport systems are integrated intrinsically into the cage, alleviating many of the synthesis issues involved in the synthetic incorporation of such functionalities. ${ }^{44} \mathrm{~A}$ considered review by Uchida et al. has outlined the properties of many of these capsids and highlighted their potential for biomedical application. ${ }^{39}$ Here we highlight specific examples which have been successfully functionalised for the biomineralisation of MBNPs.

Douglas et al.'s work on the virus protein cages: cowpea chlorotic mottle virus (CCMV) and cowpea mosaic virus (CMPV) are excellent examples of how the inherent properties of such structures can be capitalized upon. Exploitation of CCMV's intrinsic $\mathrm{pH}$ dependent gates and positively charged inner membrane; arising from the amino acid subunits which make up the viruses protein cage have thus far created a model environment for the nucleation and precipitation of both paratungstate and decavanadate, whilst the uncharged exterior of the cage remains unaffected ensuring precipitation is localised to the cage's interior. ${ }^{4,105}$ The viral capsid undergoes reversible swelling above $\mathrm{pH} 6.5$ which increases the capsid size by $10 \%$ and in turn removes the viruses intrinsic RNA, an effect of the capsids loosely coupled structure. $^{44,106}$ (Fig. 2i) This process opens up to 60 pores in the virus structure promoting diffusion in and out of the capsid core and leaving the cage free for NP synthesis, particularly where conditions above physiological $\mathrm{pH}$ are required. The fact that this process is reversible means that the reaction can be very carefully controlled by simply lowering the $\mathrm{pH}$ back below 6.5 , closing the pores with the resulting particles being constrained within the monodisperse capsids. (Fig. 2i) Many other groups have also looked into the CCMV's viability as an in vitro nanoreactor due to the viral capsids unique properties, and have yielded reactions such as creation of an environment for single enzyme studies by disassembling the protein cage (at $<\mathrm{pH} 5$ ) for the purposes of enzyme incorporation again utilising the effects of $\mathrm{pH} .{ }^{46}$ Also explored is the CCMV's binding capability to $\mathrm{Gd}^{3+}$ for MRI application. The cage has proven to be an ideal biotemplate due to the large number of possible binding sites available. This increases the payload that can be delivered for 

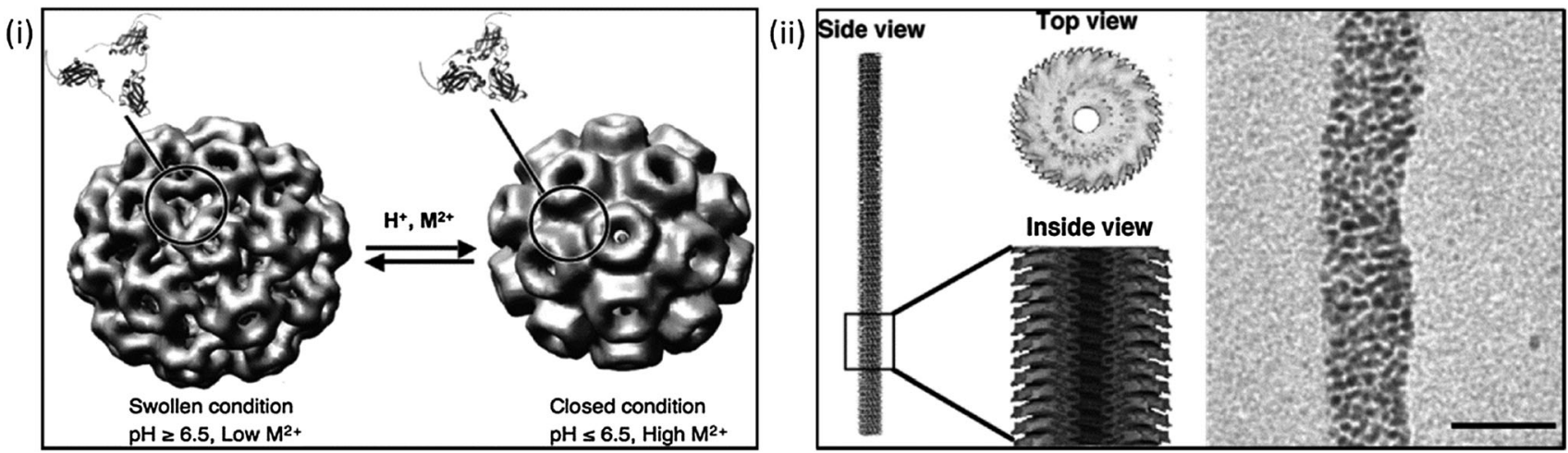

Fig. 2 Using biological templates for biomineralisation. Left: (i) manipulation of cowpea chlorotic mottle virus (CCMV) using pH conditions to aid mineralisation reactions. (Reproduced with permission from Uchida et al. ${ }^{39}$ ); right: (ii) cryo-electron micrograph and reconstruction of tobacco mosaic virus, and its use as template for the mineralisation of Pt nanoparticles. Scale bars $20 \mathrm{~nm}$ (Reproduced with permission from Uchida et al. ${ }^{39}$ and Górzny et al. ${ }^{116}$ ).

efficient application. ${ }^{107}$ CCMV functionality has also been investigated as a potential mimic for iron storage protein ferritin, again using the high number of inherent cage binding sites for accumulation and oxidative hydrolysis of ferrous ions. ${ }^{108}$ Similar work has also been carried out by the Evans lab on CPMV exploring its potential for mineralisation of gold, silica and multiple iron mineral NPs particularly exploring their viability for biomedical applications. ${ }^{109-112}$ Such a switchable process in which a nanoreactor self-assembles around the reactant, whereby the encapsulation can be $\mathrm{pH}$ controlled and nucleation can be electrostatically induced would be extremely difficult to replicate synthetically.

Protein cage templated biomineralisation is not limited to precipitation within the structures core. Biomineralisation on the exterior of CPMV has also been explored by modification of surface charge for the precipitation of both cobalt and iron oxide NPs of extremely narrow size distribution. ${ }^{109}$ Another similar structure widely studied as a potential biotemplate is the tobacco mosaic virus (TMV). Its rod-like structure is composed of helical RNA and 2130 coat proteins, the exterior of the virus can be functionalised for the binding of metal ions making it an ideal template for metal biomineralisation. The virus has been used for the $\mathrm{pH}$ controlled precipitation of Ag NPs and QDs along the internal cavity of the virus. ${ }^{113}$ The central channel of the virus has also been exploited for the biomineralisation of both $\mathrm{FePt}_{3}$ and CoPt nanowires. ${ }^{114}$ Like CCMV, the templating capability of TMV has been shown to be ideal in countless studies in which a narrow worm-like or a nano-tube of specific diameter architecture is required. Górzny et al. have shown that it is possible to use the virus structure as a template for the synthesis of Pt NPs, this increases the surface area and overall stability of the Pt nanostructures when compared to more conventional particles ${ }^{115,116}$ (Fig. 2ii). Pejoux et al. have taken a similar approach to biotemplating of $\mathrm{Ag}_{2} \mathrm{~S}$ mineralisation on the outer shell of an enzyme protein cage. ${ }^{117}$ The group exploited the properties of the shell by tuning the catalytic activity to induce crystallisation, tailoring enzymatic activity to both initiate and inhibit $\mathrm{S}^{2-}$ production as the reaction requires for semiconductor growth in the presence of the optimum concentration.
This approach has been applied to other systems suggesting it can be utilised in the synthesis of numerous other semiconductors ${ }^{117}$ in which consistently sized semiconductor NPs are required with a hollow core available for further functionality.

Protein additives. Already biomineralisation proteins from various organelles have been explored as additives in in vitro NP chemical biomineralisation reactions to improve the MBNP formation. From MTB, the magnetosome membrane specific (Mms) protein Mms6 is one of the first and most studied proteins from such a system to be utilised in this way. ${ }^{118}$ Mms6 is a membrane protein with a single transmembrane region containing acidic iron binding sites on the C-terminus. This is thought to be located on the magnetosome interior and to act as a nucleation site for particle formation. When this protein is added to an in vitro room temperature co-precipitation of magnetite there is a marked difference in the resulting particles formed. ${ }^{37,38,119}$ More recently, other MTB proteins have also being investigated such as the effects of the MTB protein MmsF on magnetite MNP morphology. MmsF is believed to be a master regulator protein in the formation of the magnetosomal NP. ${ }^{83}$ The addition of purified MmsF had a dramatic effect on particle morphology when added to a simple ambient temperature magnetite co-precipitation reaction producing monodisperse NPs with consistent morphology when compared to a control sample containing either no protein or MmsF homologue proteins. ${ }^{36}$

The diatom controls the biomineralisation of silica in a similar way using biomineralisation proteins and peptides. Again these can be added to an in vitro precipitation to improve silica formation. The isolation of a polycationic peptide called a silaffin has been shown to exert control over the precipitation of silica nanosphere networks. A lysine-lysine section within the peptide structure has proven to be responsible for the formation of the network. ${ }^{120}$ These effects are also observed with the polyanionic proteins extracted from mollusc abalone shell whose in vivo function is crystal phase switching from aragonite to calcite during the formation of nucleating protein sheets. Purification and in vitro use of these proteins can initiate the same changes in crystal phase observed within the proteins natural environment. ${ }^{121}$ 
Many more studies of this kind are ongoing, and some work is now focusing on the use of ferritin as a template for the study of these and other proteins, such as Mms6. ${ }^{122}$ Whilst this is by no means an exhaustive list of bioadditives, it demonstrates the versatility that can be achieved when we "borrow" biomineralisation protein from nature to use as additives in chemical reactions. The next step is to combine these additives into MBNP precipitation nanoreactors to simulate the proteins natural functional environment, which is already underway, with ferritin for example. Research of this type is invaluable in both confirming the natural function of these proteins; which can often be hard to identify within a biological system and to improve and simplify nanoreactor synthetic methods of mimicking biomineralisation.

\section{Biomimetic systems}

Natural biomineralisation and biokleptic templates of protein cages such as viral capsids have their limitations; constrained by only utilising the components that nature has to offer. Such nanoreactors may not be robust enough to reaction conditions outside ambient condition parameters. Taking a bottom-up approach i.e. using synthetic vesicles, means that should any new specification arise outside the biological parameters, it could be accommodated by the synthetic host, in which chemical and physical adaptions are possible. For example, if a larger compartment for mineralisation is required this can easily be optimised in vesicles with techniques such as extrusion. ${ }^{123}$ This flexibility is much less achievable with biological components such as protein cages whose evolution has been optimised by nature for their specific natural role and not the new role imposed upon them. Thus a change such as altering the nanoreactor size is unlikely to be as easily engineered.

Other issues encountered when using naturally occurring biotemplates are those of solubility and an intolerance to the conditions required for synthetic routes to precipitation, such as high temperatures and wide ranging $\mathrm{pH}$ changes, for example those used in the partial oxidation of magnetite. ${ }^{23,35}$ It is in situations such as these that research must turn to synthetic alternatives for compartmentalisation reactions and design of biomimetic nanoreactors. The benefit of creating a nanoreactor from a synthetic analogue is the ability to engineer into a scaffold the properties required for a specific mineralisation reaction ${ }^{124,125}$ which is not possible in biological systems. A key problem with crystallisation of many types of MBNPs is the harsh chemical conditions required for their uniformed synthesis. Compartmentalising within a nanoreactor massively reduces the requirement for such conditions or in some cases completely eradicates the need for organic solvents and harmful chemicals. This is particularly evident in the work by both Genc et al. ${ }^{126}$ and Pejoux et al. ${ }^{117}$ where in both cases compartmentalisation was utilised for the precipitation of gold and sulphide NPs respectively. In both examples organic solvents and harsh conditions are normally required, but by carrying out the reaction in the confines of a nanoreactor such as a lipid environment ${ }^{126}$ or an enzyme nanoreactor ${ }^{117}$ allows for the compartmentalisation to enable a move toward greener chemistry synthetic routes.
Liposomes. A nanoreactor can be created by the encapsulation of one reagent within the confines of a vesicle which will facilitate the completion of a reaction. ${ }^{28}$ Lipid vesicles; or liposomes are perhaps the obvious choice for a nanoreactor, due to their extensive utilisation in nature, and as such they have been subjected to extensive amount of research and characterisation as well as their applicability to wide range of applications. ${ }^{17,48-50}$ Their encapsulation abilities have been widely explored and are wide ranging such as in the study by Tan et al., who demonstrates the encapsulation of moieties ranging from whole cells to single proteins via just one preparation method. ${ }^{127}$ Other studies by Monnard ${ }^{128}$ and Tester ${ }^{129}$ previously outlined the properties of a liposome required for it to function as a nanoreactor. There are several classifications of liposome dependent on their composition and eventual application which include multivesicular and multilamellar structures or simply unilamellar vesicles all of which can range in size from 10's of nanometers (small unilamellar vesicles) up to the micron range generally classified as giant unilamellar vesicles. ${ }^{50}$ There are also multiple different structures and architectures possible via various liposome preparation methods with vesicles ranging from $\mathrm{nm}$ to 10's of $\mu \mathrm{m}$ 's in size, able to form more complex multilamellar and multivesicular structures as well as nano-tubes, which have previously been utilised in studies to mimic exocytosis. ${ }^{49}$ There are a number of routes to form liposomes including but not limited to; sonication, electroformation extrusion, inkjetting and microfluidics. ${ }^{48,50,130}$ These different preparation methods allow for multiple modes of encapsulation and in some case encapsulation of multiple reagents. More complicated preparation methods can allow for the independent design of the inner and outer leaflet of a liposomal nanoreactor such as the inverted emulsion method developed by Pautot et al. ${ }^{131,132}$ Inverted emulsion allows for production of vesicles capable of withstanding two contrasting external and internal environments widening the scope of reaction type that liposomal nanoreactors can be subjected to, particularly in cases of immiscible solutions. ${ }^{131,132}$

Membrane transport across the liposome bilayer can be initiated by careful control of both the inner and outer pHs. Osmotic effects can be used to aid transmembrane diffusion, by increase or decrease of the outer vesicular $\mathrm{pH}$ it is possible to force diffusion across the membrane. ${ }^{133}$ Ongoing studies are working toward better quantifying the effect of $\mathrm{pH}$ on membrane transport. ${ }^{134,135}$ It has also been demonstrated that $\mathrm{pH}$ changes can result in full structural changes. ${ }^{136}$ The presence of a lipid bilayer (wall to the nanoreactors) can often aid compartmentalised reactions, by adsorption of ions on to the membrane surface which then facilitates the consequent nucleation. This nucleation and subsequent crystal growth process is limited to the size of the internal vesicle diameter, ensuring the production of NPs of monodisperse size; this effect is observed in the growth of CdS, ZnCdS and HgCdS nanocrystal QDs within the core of liposome. ${ }^{137,138}$ The authors were successful in controlling synthesis to 1 particle per vesicle using membrane mediated crystal growth $^{137}$ a ratio which could not have been achieved with post synthesis incorporation into vesicles, for biomedical application to lessen QD toxicity issues. 
Liposomes offer the perfect vehicle for a biomimetic approach to synthetic biomineralisation. An excellent example is that of biomimicing the biomineralisation of a magnetosome within MTB. ${ }^{42}$ Vesicles are an ideal environment to create this supersaturated environment, evident in the work of Mann and Hannington $^{42,139}$ and their work toward the creation of a biomimetic magnetosome. Compartmentalisation of a reaction forces a supersaturated environment and the consequent nucleation processes involved in crystallisation of the magnetite MNPs. This approach has also been applied to the biomimetic biomineralisation of calcite, aragonite, hydroxyapatite and silica ${ }^{140}$ demonstrating flexibility and diversity with regards to the reactions which can be incorporated into a single biomimetic system. Ongoing research has expanded this field further such as, the design of the "magnetonion" a multilamellar vesicle, resembling an onion-like structure in which MNPs sit within the layers of the "onion" by Faure et al. ${ }^{141}$ and Sangregorio et al. ${ }^{142}$ both of these systems build on Mann and Hannington's biomimetic system, but none have thus far achieved a comprehensive mimetic of a magnetosome functional for bioapplication. Much of the work in our own lab builds on Mann's initial biomimetic research, ${ }^{143}$ with ours focusing on trying to further understand the formation and biomineralisation processes observed in the magnetosome. To this effect, in our lab we are currently developing an artificial magnetosome nanoreactor.

Other groups such as Chakrabarti et al., have also explored taking a biomimetic approach to the creation of a nanoreactor, by the addition of a divalent specific ion channel. The study has shown how biological components can be incorporated into synthetic vesicles to mimic the ion transport processes observed in nature. This was proven by the loading both $\mathrm{Fe}^{2+}$ and $\mathrm{Ba}^{2+}$ into preformed liposomes via liposomal incorporation of $\mathrm{Ca}^{2+}$ ionophore A23187. ${ }^{144}$ Studies such as this and others ${ }^{134}$ are critical to the development of synthetic biology for the creation of novel biomimetic biomineralisation nanoreactors.

Polymersomes. One major advantage of using synthetic amphiphiles such as block copolymers is the wide range of architectures achievable by optimisation of both the polymer hydrophobicity and monomer block lengths ${ }^{145}$ (Fig. 3i). The architectures achieved by block copolymers can affect both the application they are suitable for and their effectiveness in those applications. These architectures and their effectiveness in compartmentalisation of NPs are outlined in the review by Mai and Eisenberg ${ }^{43}$ as well as their potential biocompatibility. ${ }^{146}$

(i)

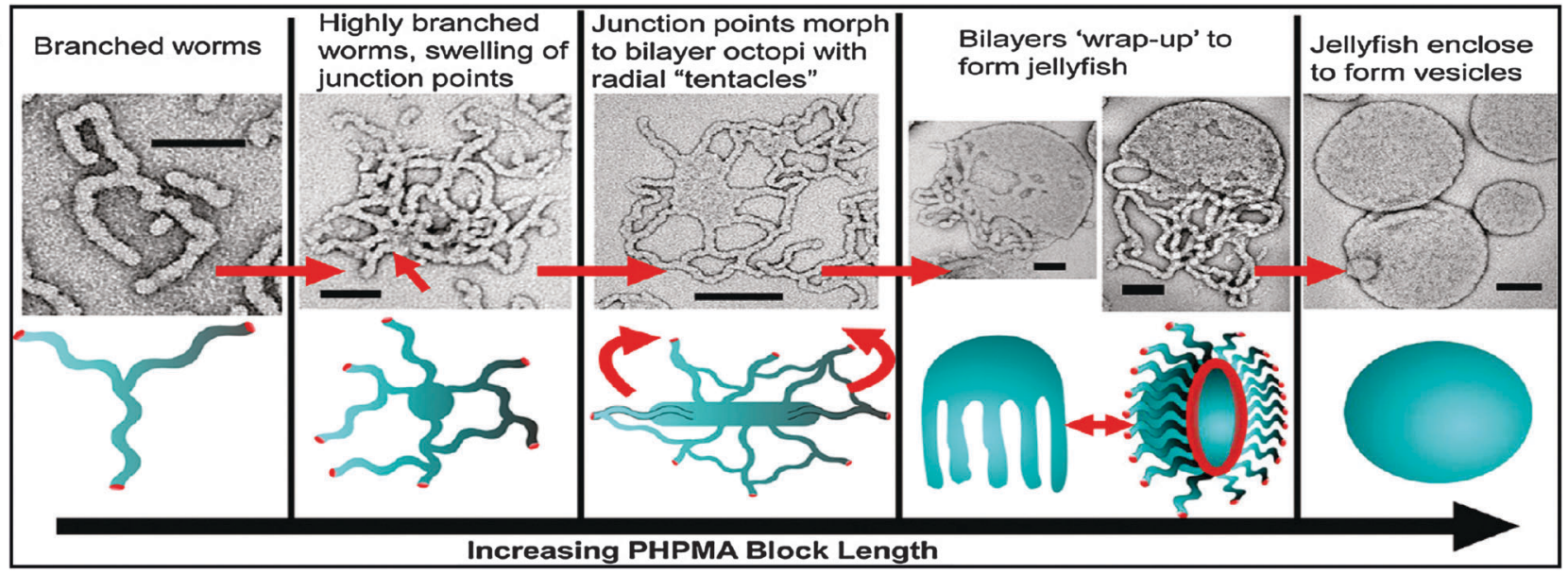

(ii)

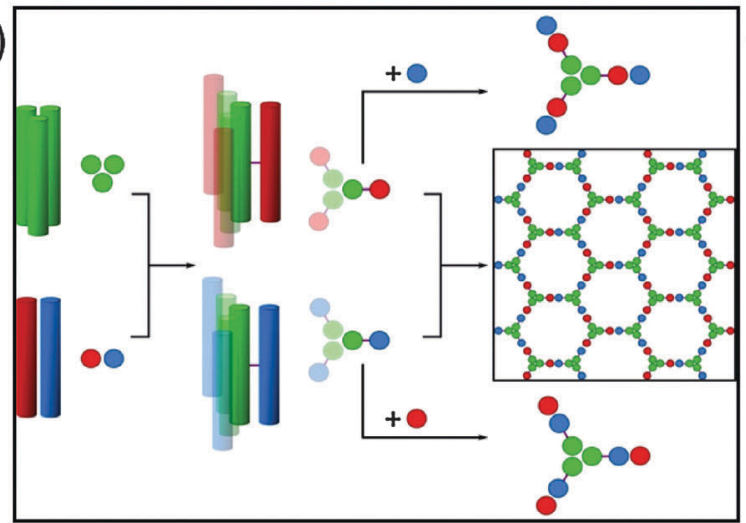

(iii)

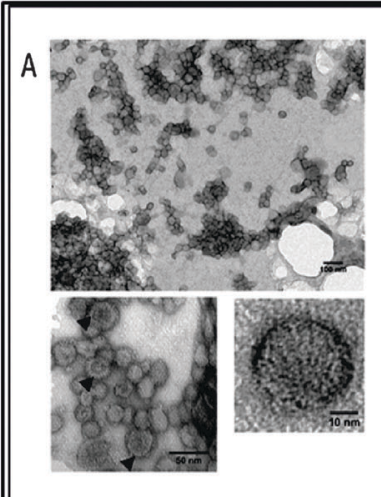

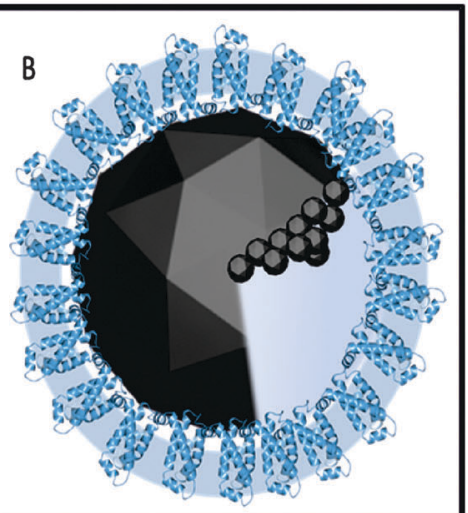

Fig. 3 Biomimetic mineralisation systems. Top: (i) schematic and electron microscopy interpretation of architectures achievable during polymersome synthesis demonstrating the potential for control of the formation of a polymeric nanoreactor; (reprinted with permission from A. Blanazs, et al., J. Am. Chem. Soc., 2011 Copyright (2011) American Chemical Society). Bottom left: (ii) schematic of peptide SAGE cage synthesis which takes a bottom-up approach to nanoreactor design (reproduced with permission from Fletcher et al. ${ }^{159}$ ); bottom right: (iii) (A) transmission electron micrograph of selfassembled MmsF proteinosomes. (B) Schematic of potential proteinosome biomineralisation pathways (adapted with permission from Rawlings et al. ${ }^{36}$ ). 
Polymersome synthesis can occur via numerous methods such as, film rehydration, electroformation, ${ }^{47,147}$ RAFT synthesis, ${ }^{145,148}$ ring opening polymerisation, ${ }^{149,150}$ layer by layer polyelectrolyte formation utilising charge and more complex methods such as shell cross-linked NPs, ${ }^{151}$ Polymer self-assembly improves efficiency in living radical polymerisation reactions narrowing the polydispersity and increasing end functionality. ${ }^{152}$ For these reasons block copolymers are emerging as novel materials for the creation of nanoreactors, particularly in the field of drug delivery. ${ }^{148,153,154}$ The diversity observed in the formation methods of polymersomes is reflected in the almost endless combination of properties that can be incorporated into a polymersome by careful selection and design of the buildingblock polymer materials. For example, the structures achievable with the polymer poly(glycerol monomethacrylate)-poly(2-hydroxypropyl methacrylate), (PGMA-PHMPA) demonstrated by Blanazs et $a l .{ }^{145}$ are evidential of the ease with which the a polymeric nanoreactor can be tailored to suit a desired application. This study demonstrated by simple extension of polymer block length we can easily move from worm-like structures, through more complex intermediates termed "octopi" and "jellyfish" resulting in vesicles at the longest hydrophobic block length. (Fig. 3i). ${ }^{145,148,155}$ Each of the structures bring their own properties to a nanoreactor, for example the decision to form a worm-like or tube nanoreactor will inevitably templates a wire-like MBNP and it is possible to extend in vivo lifetime of a nanoreactor when compared to a more vesicle-like structure.

Polymersomes as nanoreactors is a relatively new field, with increasing success. Meier et al. have successfully incorporated biological components into polymer membranes, ${ }^{156}$ this work has been further advanced by numerous other groups by incorporation of both protein channels and enzymes. ${ }^{157}$ Much of this work is outlined in the review by Meier et al. ${ }^{158}$ which demonstrates a framework of polymersome nanoreactors for the study of ion transporters, membrane proteins and as biomineralisation scaffolds. Therefore this suggests that block copolymers vesicles are now competing with liposomes in their use as vehicles for both the study of biological moieties and as successful nanoreactors.

Artificial self-assembly scaffold proteins as nanoreactors. There is also ongoing work in many groups into the design of new biotemplates, again built from individual biological components; both naturally occurring and synthetic. For example the Woolfson lab has developed a self-assembled peptide cage or "SAGE", which are cleverly designed synthetic coiled-coil peptide assemblies' utilising hydrophobic and electrostatic interactions. These peptides essentially act as building blocks for a fully synthetic peptide cage ${ }^{159}$ (Fig. 3ii). Similar approaches to biotemplate design have also been taken by Gradišar et al. ${ }^{160}$ again exploiting a coiled-coil assembly, while Lai et al. ${ }^{161}$ utilise protein-protein interactions to force their assembly into a novel protein cage. The work in our own laboratory has also recently uncovered a protein-protein assembly; with the discovery that purified MTB protein MmsF self-assembles in aqueous solution to form a vesicle-like structure composed entirely of protein; a "proteinosome",36 (Fig. 3iii). The development of these types of structures and others are opening up new avenues in complete bottom-up design of novel nanoreactors, biotemplates and compartments offering a future of opportunities for tailored biomimetic mineralisation of a range of MBNPs.

\section{Conclusions and future outlook}

The use of a nanoreactor to biomineralise MBNPs has advanced many areas of research and the development of future applications. Studies of biological components in vitro have already advanced understanding of biomineralisation processes in nature. ${ }^{36,37,119}$

There is continuing exploration of biology's effectiveness in internal compartmentalisation of chemical reactions, and how this can result in perfectly biomineralised MBNPs. This knowledge is invaluable in understanding the multiple physiological processes and the function of numerous biological components involved in both the transport and morphological control observed for biomineralisation in natural nanoreactors, which serves to aid fundamental understanding of the processes and advance the development of novel nanomaterials.

Advancement in this field has found that synthesis of MBNPs within a nanoreactor mimicking biomineralisation offers a range of superior properties and functionality. The benefits for nanomedicinal materials are extensive, with the scope of applicability of MBNPs ever widening. Such benefits include: a higher degree of precision and reproducibility with respect to size and morphology across the entire population of particles; the fact this can be "switched" by stimuli such as $\mathrm{pH}$ change; the intrinsic inclusion of a biocompatible coating, which can be readily biofunctionalised for further application. MBNPs can also often prove toxic in vivo. Compartmentalisation of such reactions removes the need for post formation processing and coating to remove toxicity. Additionally, this superior control over MBNP formation is achieved under ambient environmentally-friendly reaction conditions. Research now allows us to finely tune both the structure and properties of a nanoreactor. From the mutation of single amino acids to change the outcome of mineralisation reaction, to completely altering the architecture and size of a nanoreactor in the case of PGMA-PHMPA polymersomes. It can be seen that the further we move towards fully synthetic nanoreactors, the levels of complexity observe in naturally occurring nanoreactors are removed, and we able to then fully tailor the properties to our requirements.

Escosura et $a{ }^{35}{ }^{35}$ writes that whilst the creation of a fully functional biomimetic nanocontainer may be just out of reach of today's research, nobody can doubt that great understanding and numerous beneficial bioinspired nanoreactors with applications in multiple fields have been and will be discovered along the way. With this sentiment in mind the pathway to the future biomimetic production of monodisperse MBNP has shed real light on the nano and microscale encapsulated biomineralisation process. Although the fully functional biomimetic nanocontainer is out of reach of today's research, tomorrow is getting ever closer and we believe we are on the verge of this goal. 
In order to achieve this for nanoreactor synthesis of MBNP there is vast opportunities in exploiting a combination of biological materials and designed artificial self-assembly materials to design and engineer nanoreactors of ideal specification (robust to chemical environment, biocompatible, mono-dispersed, switchable etc.) and incorporate other functionality such as further biomedical therapeutics on exterior and biomineralisation controlling species on the interior. Ultimately, the design and mixing of biology and biomimicry has led to nanoreactors that are perfectly poised to move from the bench to the bedside.

\section{Acknowledgements}

We would like to thank the EPSRC (EP/I032355/2) for funding the authors. We would also like to thank Dr Andrea Rawlings, Mr Scott Bird and Miss Lori Somner (University of Sheffield, Department of Chemistry) and Dr Jonathan Bramble (IBIOS, University of Nottingham) for their support and useful discussions.

\section{References}

1 Q. A. Pankhurst, J. Connolly, S. Jones and J. Dobson, J. Phys. D: Appl. Phys., 2003, 36, R167-R181.

2 Y.-w. Jun, Y.-M. Huh, J.-s. Choi, J.-H. Lee, H.-T. Song, S. Kim, S. Yoon, K.-S. Kim, J.-S. Shin, J.-S. Suh and J. Cheon, J. Am. Chem. Soc., 2005, 127, 5732-5733.

3 Y. Du, P. Lai, C. Leung and P. Pong, Int. J. Mol. Sci., 2013, 14, 18682-18710.

4 E. Alphandéry, F. Guyot and I. Chebbi, Int. J. Pharm., 2012, 434, 444-452.

5 C. S. S. R. Kumar and F. Mohammad, Adv. Drug Delivery Rev., 2011, 789-808.

6 Q. A. Pankhurst, J. Connolly, S. K. Jones and J. Dobson, J. Phys. D: Appl. Phys., 2003, 36, R167-R181.

7 K. Saha, S. S. Agasti, C. Kim, X. Li and V. M. Rotello, Chem. Rev., 2012, 112, 2739-2779.

8 S. Zeng, K.-T. Yong, I. Roy, X.-Q. Dinh, X. Yu and F. Luan, Plasmonics, 2011, 6, 491-506.

9 S. Ghaderi, B. Ramesh and A. M. Seifalian, J. Drug Targeting, 2011, 19, 475-486.

10 H. Ron, Environ. Health Perspect., 2006, 114, 165-172.

11 Q. Pankhurst, N. Thanh, S. Jones and J. Dobson, J. Phys. D: Appl. Phys., 2009, 42, 224001.

12 J. Dobson, Drug Dev. Res., 2006, 67, 55-60.

13 J. Dobson, Nanomedicine, 2006, 1, 31-37.

14 D. C. Drummond, M. Zignani and J. Leroux, Prog. Lipid Res., 2000, 39, 409-460.

15 S. M. Janib, A. S. Moses and J. A. MacKay, Adv. Drug Delivery Rev., 2010, 62, 1052-1063.

16 A. Singh, F. Dilnawaz, S. Mewar, U. Sharma, N. R. Jagannathan and S. K. Sahoo, ACS Appl. Mater. Interfaces, 2011, 3, 842-856.

17 W. T. Al-Jamal and K. Kostarelos, Acc. Chem. Res., 2011, 44, 1094-1104.

18 P. B. Santhosh and N. P. Ulrih, Cancer Lett., 2013, 8-17.

19 S. Svenson, Mol. Pharmaceutics, 2013, 848-856.
20 C. B. Murray, D. J. Norris and M. G. Bawendi, J. Am. Chem. Soc., 1993, 115, 8706-8715.

21 C.-H. Ho, C.-P. Tsai, C.-C. Chung, C.-Y. Tsai, F.-R. Chen, H.-J. Lin and C.-H. Lai, Chem. Mater., 2011, 23, 1753-1760.

22 P. Raveendran, J. Fu and S. L. Wallen, J. Am. Chem. Soc., 2003, 125, 13940-13941.

23 A. E. Regazzoni, G. A. Urrutia, M. A. Blesa and A. J. G. Maroto, J. Inorg. Nucl. Chem., 1981, 43, 1489-1493.

24 S. Asuha, B. Suyala, X. Siqintana and S. Zhao, J. Alloys Compd., 2011, 509, 2870-2873.

25 Y. K. Jeong, D. K. Shin, H. J. Lee, K. S. Oh, J. H. Lee and D. H. Riu, in Science of Engineering Ceramics III, ed. T. Ohji, T. Sekino and K. Niihara, 2006, vol. 317-318, pp. 203-206.

26 H. Steen and V. Schwenger, Pediatr. Nephrol., 2007, 22, 1239-1242.

27 S. E. Greene and A. Komeili, Curr. Opin. Cell Biol., 2012, 24, 490-495.

28 D. M. Vriezema, M. Comellas Aragonès, J. A. Elemans, J. J. Cornelissen, A. E. Rowan and R. J. Nolte, Chem. Rev., 2005, 105, 1445-1490.

29 S. Mann, Acc. Chem. Res., 2012, 45, 2131-2141.

30 A. J. Dzieciol and S. Mann, Chem. Soc. Rev., 2012, 41, 79-85.

31 S. Mann, Biomimetic materials chemistry, John Wiley \& Sons, 1995.

32 R. Roodbeen and J. van Hest, BioEssays, 2009, 31, 1299-1308.

33 V. Noireaux, R. Bar-Ziv, J. Godefroy, H. Salman and A. Libchaber, Phys. Biol., 2005, 2, P1.

34 D. G. Gibson, J. I. Glass, C. Lartigue, V. N. Noskov, R.-Y. Chuang, M. A. Algire, G. A. Benders, M. G. Montague, L. Ma, M. M. Moodie, C. Merryman, S. Vashee, R. Krishnakumar, N. Assad-Garcia, C. Andrews-Pfannkoch, E. A. Denisova, L. Young, Z.-Q. Qi, T. H. Segall-Shapiro, C. H. Calvey, P. P. Parmar, C. A. Hutchison, H. O. Smith and J. C. Venter, Science, 2010, 329, 52-56.

35 A. de la Escosura, R. J. Nolte and J. J. Cornelissen, J. Mater. Chem., 2009, 19, 2274-2278.

36 A. E. Rawlings, J. P. Bramble, R. Walker, J. Bain, J. M. Galloway and S. S. Staniland, Proc. Natl. Acad. Sci. U. S. A., 2014, 111, 16094-16099.

37 Y. Amemiya, A. Arakaki, S. S. Staniland, T. Tanaka and T. Matsunaga, Biomaterials, 2007, 28, 5381-5389.

38 M. Tanaka, E. Mazuyama, A. Arakaki and T. Matsunaga, J. Biol. Chem., 2011, 286, 6386-6392.

39 M. Uchida, M. T. Klem, M. Allen, P. Suci, M. Flenniken, E. Gillitzer, Z. Varpness, L. O. Liepold, M. Young and T. Douglas, Adv. Mater., 2007, 19, 1025-1042.

40 C. J. Stephens, Y.-Y. Kim, S. D. Evans, F. C. Meldrum and H. K. Christenson, J. Am. Chem. Soc., 2011, 133, 5210-5213.

41 C. J. Stephens, S. F. Ladden, F. C. Meldrum and H. K. Christenson, Adv. Funct. Mater., 2010, 20, 2108-2115.

42 S. Mann, J. P. Hannington and R. J. P. Williams, Nature, 1986, 324, 565-567.

43 Y. Mai and A. Eisenberg, Acc. Chem. Res., 2012, 1657-1666. 44 T. Douglas and M. Young, Nature, 1998, 393, 152-155.

45 M. Allen, D. Willits, J. Mosolf, M. Young and T. Douglas, Adv. Mater., 2002, 14, 1562-1565. 
46 M. Comellas-Aragones, H. Engelkamp, V. I. Claessen, N. A. J. M. Sommerdijk, A. E. Rowan, P. C. M. Christianen, J. C. Maan, B. J. M. Verduin, J. J. L. M. Cornelissen and R. J. M. Nolte, Nat. Nanotechnol., 2007, 2, 635-639.

47 B. M. Discher, Y.-Y. Won, D. S. Ege, J. C.-M. Lee, F. S. Bates, D. E. Discher and D. A. Hammer, Science, 1999, 284, 1143-1146.

48 M. L. Immordino, F. Dosio and L. Cattel, Int. J. Nanomed., 2006, 1, 297-315.

49 A. Jesorka and O. Orwar, Annual Review of Analytical Chemistry, 2008, vol. 1, pp. 801-832.

50 B. Maherani, E. Arab-Tehrany, M. R. Mozafari, C. Gaiani and M. Linder, Curr. Nanosci., 2011, 7, 436-452.

51 S. K. P. Velu, M. Yan, K.-P. Tseng, K.-T. Wong, D. M. Bassani and P. Terech, Macromolecules, 2013, 46, 1591-1598.

52 D. E. Discher, V. Ortiz, G. Srinivas, M. L. Klein, Y. Kim, D. Christian, S. Cai, P. Photos and F. Ahmed, Prog. Polym. Sci., 2007, 32, 838-857.

53 Y. Lu, L. Dong, L.-C. Zhang, Y.-D. Su and S.-H. Yu, Nano Today, 2012, 7, 297-315.

54 M. Bonini, D. Berti and P. Baglioni, Curr. Opin. Colloid Interface Sci., 2013, 18, 459-467.

55 K. T. Kim, S. A. Meeuwissen, R. J. Nolte and J. C. van Hest, Nanoscale, 2010, 2, 844-858.

$56 \mathrm{~J}$. L. Kirschvink and J. W. Hagadorn, The Biomineralisation of Nano-and Micro-Structures, Wiley-VCH Verlag $\mathrm{GmbH}$, Weinheim, Germany, 2000, pp. 139-150.

57 H. Skinner and A. Jahren, Treatise Geochem., 2003, 8, 117-184.

58 P. Westbroek, J. Young and K. Linschooten, J. Protozool., 1989, 36, 368-373.

59 J. R. Young, S. A. Davis, P. R. Bown and S. Mann, J. Struct. Biol., 1999, 126, 195-215.

60 M. Hildebrand, Chem. Rev., 2008, 108, 4855.

61 C. M. Niemeyer and C. A. Mirkin, Nanobiotechnology: concepts, applications and perspectives, John Wiley \& Sons, 2006.

62 S. Abe, J. Niemeyer, M. Abe, Y. Takezawa, T. Ueno, T. Hikage, G. Erker and Y. Watanabe, J. Am. Chem. Soc., 2008, 130, 10512-10514.

63 T. Ueno, M. Suzuki, T. Goto, T. Matsumoto, K. Nagayama and Y. Watanabe, Angew. Chem., 2004, 116, 2581-2584.

64 Y. Tao, H. Kanoh, L. Abrams and K. Kaneko, Chem. Rev., 2006, 106, 896-910.

65 T. S. Koblenz, J. Wassenaar and J. N. Reek, Chem. Soc. Rev., 2008, 37, 247-262.

66 J. L. Kirschvink, A. Kobayashi-Kirschvink and B. J. Woodford, Proc. Natl. Acad. Sci. U. S. A., 1992, 89, 7683-7687.

67 R. Blakemore, Science, 1975, 190, 377.

68 D. Faivre and D. Schüler, Chem. Rev., 2008, 108, 4875-4898.

69 Y. A. Gorby, T. J. Beveridge and R. P. Blakemore, J. Bacteriol., 1988, 170, 834.

70 C. Jogler and D. Schüler, Annu. Rev. Microbiol., 2009, 63, 501-521.

71 D. H. Nies, Mol. Microbiol., 2011, 82, 792-796.

72 A. Arakaki, H. Nakazawa, M. Nemoto, T. Mori and T. Matsunaga, J. R. Soc., Interface, 2008, 5, 977-999.
73 R. B. Frankel, R. P. Blakemore and R. S. Wolfe, Science, 1979, 203, 1355.

74 R. B. Frankel and R. P. Blakemore, Bioelectromagnetics, 1989, 10, 223-237.

75 D. A. Bazylinski and R. B. Frankel, Nat. Rev. Microbiol., 2004, 2, 217-230.

76 M. Smith, P. Sheehan, L. Perry, K. O'Connor, L. Csonka, B. Applegate and L. Whitman, Biophys. J., 2006, 91, 1098-1107.

77 W. F. Guerin and R. P. Blakemore, Appl. Environ. Microbiol., 1992, 58, 1102-1109.

78 R. P. Blakemore, Annu. Rev. Microbiol., 1982, 36, 217-238.

79 R. Frankel, Chin. J. Oceanol. Limnol., 2009, 27, 1-2.

80 H. Nudelman and R. Zarivach, Front. Microbiol., 2014, 5, 9.

81 A. Komeili, Z. Li, D. K. Newman and G. J. Jensen, Science, 2006, 311, 242-245.

82 J. F. Stolz, S.-B. R. Chang and J. L. Kirschvink, Nature, 1986, 321, 849-851.

83 D. Murat, V. Falahati, L. Bertinetti, R. Csencsits, A. Körnig, K. Downing, D. Faivre and A. Komeili, Mol. Microbiol., 2012, 684-699.

84 R. Uebe, K. Junge, V. Henn, G. Poxleitner, E. Katzmann, J. M. Plitzko, R. Zarivach, T. Kasama, G. Wanner and M. Pósfai, Mol. Microbiol., 2011, 818-835.

85 K. Grünberg, E.-C. Müller, A. Otto, R. Reszka, D. Linder, M. Kube, R. Reinhardt and D. Schüler, Appl. Environ. Microbiol., 2004, 70, 1040-1050.

86 T. Matsunaga, M. Nemoto, A. Arakaki and M. Tanaka, Proteomics, 2009, 9, 3341-3352.

87 M. Tanaka, Y. Okamura, A. Arakaki, T. Tanaka, H. Takeyama and T. Matsunaga, Proteomics, 2006, 6, 5234-5247.

88 C. Lang, D. Schüler and D. Faivre, Macromol. Biosci., 2007, 7, 144-151.

89 T. Prozorov, D. A. Bazylinski, S. K. Mallapragada and R. Prozorov, Mater. Sci. Eng., R, 2013, 74, 133-172.

90 T. Tanaka, K. Maruyama, K. Yoda, E. Nemoto, Y. Udagawa, H. Nakayama, H. Takeyama and T. Matsunaga, Biosens. Bioelectron., 2003, 19, 325-330.

91 T. Yoshino, F. Kato, H. Takeyama, M. Nakai, Y. Yakabe and T. Matsunaga, Anal. Chim. Acta, 2005, 532, 105-111.

92 T. Tanaka and T. Matsunaga, Anal. Chem., 2000, 72, 3518-3522.

93 K. Sode, S. Kudo, T. Sakaguchi, N. Nakamura and T. Matsunaga, Biotechnol. Tech., 1993, 7, 688-694.

94 B. Yoza, A. Arakaki and T. Matsunaga, J. Biotechnol., 2003, 101, 219-228.

95 F. C. Meldrum, T. Douglas, S. Levi, P. Arosio and S. Mann, J. Inorg. Biochem., 1995, 58, 59-68.

96 K. K. W. Wong and S. Mann, Adv. Mater., 1996, 8, 928-932. 97 S. Mann and F. C. Meldrum, Adv. Mater., 1991, 3, 316-318.

98 B. Warne, O. I. Kasyutich, E. L. Mayes, J. A. Wiggins and K. K. Wong, IEEE Trans. Magn., 2000, 36, 3009-3011.

99 F. C. Meldrum, B. R. Heywood and S. Mann, Science, 1992, 257, 522-523.

100 K. Zeth, S. Offermann, L.-O. Essen and D. Oesterhelt, Proc. Natl. Acad. Sci. U. S. A., 2004, 101, 13780-13785. 
101 W. Zhong, D. Alexeev, I. Harvey, M. Guo, D. J. Hunter, H. Zhu, D. J. Campopiano and P. J. Sadler, Angew. Chem., Int. Ed., 2004, 43, 5914-5918.

102 J. Schemberg, K. Schneider, U. Demmer, E. Warkentin, A. Müller and U. Ermler, Angew. Chem., 2007, 119, 2460-2465.

103 D. Alexeev, H. Zhu, M. Guo, W. Zhong, D. J. Hunter, W. Yang, D. J. Campopiano and P. J. Sadler, Nat. Struct. Mol. Biol., 2003, 10, 297-302.

104 Y. Shin, A. Dohnalkova and Y. Lin, J. Phys. Chem. C, 2010, 114, 5985-5989.

105 J. E. Johnson and J. A. Speir, J. Mol. Biol., 1997, 269, 665-675.

106 J. A. Speir, S. Munshi, G. Wang, T. S. Baker and J. E. Johnson, Structure, 1995, 3, 63-78.

107 M. Allen, J. W. Bulte, L. Liepold, G. Basu, H. A. Zywicke, J. A. Frank, M. Young and T. Douglas, Magn. Reson. Med., 2005, 54, 807-812.

108 T. Douglas, E. Strable, D. Willits, A. Aitouchen, M. Libera and M. Young, Adv. Mater., 2002, 14, 415-418.

109 A. A. Aljabali, J. E. Barclay, O. Cespedes, A. Rashid, S. S. Staniland, G. P. Lomonossoff and D. J. Evans, Adv. Funct. Mater., 2011, 21, 4137-4142.

110 A. A. Aljabali, S. Shukla, G. P. Lomonossoff, N. F. Steinmetz and D. J. Evans, Mol. Pharmaceutics, 2012, 10, 3-10.

111 A. M. Wen, S. Shukla, P. Saxena, A. A. Aljabali, I. Yildiz, S. Dey, J. E. Mealy, A. C. Yang, D. J. Evans and G. P. Lomonossoff, Biomacromolecules, 2012, 13, 3990-4001.

112 N. F. Steinmetz, S. N. Shah, J. E. Barclay, G. Rallapalli, G. P. Lomonossoff and D. Evans, Small, 2009, 5, 813-816.

113 E. Dujardin, C. Peet, G. Stubbs, J. N. Culver and S. Mann, Nano Lett., 2003, 3, 413-417.

114 R. Tsukamoto, M. Muraoka, M. Seki, H. Tabata and I. Yamashita, Chem. Mater., 2007, 19, 2389-2391.

115 M. Ł. Górzny, A. Walton, M. Wnk, P. Stockley and S. Evans, Nanotechnology, 2008, 19, 165704.

116 M. Ł. Górzny, A. S. Walton and S. D. Evans, Adv. Funct. Mater., 2010, 20, 1295-1300.

117 C. Pejoux, R. de la Rica and H. Matsui, Small, 2010, 6, 999-1002.

118 A. Arakaki, J. Webb and T. Matsunaga, J. Biol. Chem., 2003, 278, 8745-8750.

119 J. M. Galloway, A. Arakaki, F. Masuda, T. Tanaka, T. Matsunaga and S. S. Staniland, J. Mater. Chem., 2011, 21, 15244-15254.

120 N. Kröger, R. Deutzmann and M. Sumper, Science, 1999, 286, 1129-1132.

121 A. M. Belcher, X. H. Wu, R. J. Christensen, P. K. Hansma, G. D. Stucky and D. E. Morse, Nature, 1996, 381, 56-58.

122 M. Neeman, R. Zarivach, M. Radoul, B. Cohen, M. Vandsburger and L. Lewin, US 13/856,788, 2013.

123 L. D. Mayer, M. J. Hope and P. R. Cullis, Biochim. Biophys. Acta, Biomembr., 1986, 858, 161-168.

124 S. Ganta, H. Devalapally, A. Shahiwala and M. Amiji, J. Controlled Release, 2008, 126, 187-204.

125 D. Schmaljohann, Adv. Drug Delivery Rev., 2006, 58, 1655-1670.
126 R. Genc, G. Clergeaud, M. Ortiz and C. O’Sullivan, Biomater. Sci., 2014, 1128-1134.

127 Y.-C. Tan, K. Hettiarachchi, M. Siu, Y.-R. Pan and A. P. Lee, J. Am. Chem. Soc., 2006, 128, 5656-5658.

128 P. A. Monnard, J. Membr. Biol., 2003, 191, 87-97.

129 C. C. Tester, C.-H. Wu, S. Weigand and D. Joester, Faraday Discuss., 2012, 159, 345-356.

130 P. Walde, K. Cosentino, H. Engel and P. Stano, ChemBioChem, 2010, 11, 848-865.

131 S. Pautot, B. J. Frisken and D. Weitz, Proc. Natl. Acad. Sci. U. S. A., 2003, 100, 10718.

132 S. Pautot, B. J. Frisken and D. A. Weitz, Langmuir, 2003, 19, 2870-2879.

133 S. Mann, M. J. Kime, R. G. Ratcliffe and R. J. P. Williams, J. Chem. Soc., Dalton Trans., 1983, 771-774.

134 M. Megens, C. E. Korman, C. M. Ajo-Franklin and D. A. Horsley, Biochim. Biophys. Acta, Biomembr., 2014, 2420-2424.

135 E. Mamasheva, C. O'Donnell, A. Bandekar and S. Sofou, Mol. Pharmaceutics, 2011, 8, 2224-2232.

136 C.-Y. Leung, L. C. Palmer, B. F. Qiao, S. Kewalramani, R. Sknepnek, C. J. Newcomb, M. A. Greenfield, G. Vernizzi, S. I. Stupp and M. J. Bedzyk, ACS Nano, 2012, 6, 10901-10909.

137 M. T. Kennedy, B. A. Korgel, H. G. Monbouquette and J. A. Zasadzinski, Chem. Mater., 1998, 10, 2116-2119.

138 B. A. Korgel and H. G. Monbouquette, Langmuir, 2000, 16, 3588-3594.

139 S. Mann and J. P. Hannington, J. Colloid Interface Sci., 1988, 122, 326-335.

140 S. Mann and R. J. P. Williams, J. Chem. Soc., Dalton Trans., 1983, 311-316.

141 C. Faure, M.-E. Meyre, S. Trépout, O. Lambert and E. Lebraud, J. Phys. Chem. B, 2009, 113, 8552-8559.

142 C. Sangregorio, J. K. Wiemann, C. J. O'Connor and Z. Rosenzweig, J. Appl. Phys., 1999, 85, 5699-5701.

143 S. Mann, J. P. Hannington and R. J. P. Williams, Nature, 1986, 324, 565-567.

144 A. C. Chakrabarti, J. A. Veiro, N. S. Wong, J. J. Wheeler and P. R. Cullis, Biochim. Biophys. Acta, Biomembr., 1992, 1108, 233-239.

145 A. Blanazs, J. Madsen, G. Battaglia, A. J. Ryan and S. P. Armes, J. Am. Chem. Soc., 2011, 267-277.

146 C. W. Evans, M. Fitzgerald, T. D. Clemons, M. J. House, B. S. Padman, J. A. Shaw, M. Saunders, A. R. Harvey, B. Zdyrko, I. Luzinov, G. A. Silva, S. A. Dunlop and K. S. Iyer, ACS Nano, 2011, 5, 8640-8648.

147 D. E. Discher and A. Eisenberg, Science, 2002, 297, 967-973.

148 A. Blanazs, S. P. Armes and A. J. Ryan, Macromol. Rapid Commun., 2009, 30, 267-277.

149 F. Zhang, J. A. Smolen, S. Zhang, R. Li, P. N. Shah, S. Cho, H. Wang, J. E. Raymond, C. L. Cannon and K. L. Wooley, Nanoscale, 2015, 7, 2265-2270.

150 J.-F. Lutz, Nat. Chem., 2010, 2, 84-85.

151 Q. Zhang, E. E. Remsen and K. L. Wooley, J. Am. Chem. Soc., 2000, 122, 3642-3651. 
152 P. B. Zetterlund, Polym. Chem., 2011, 2, 534-549.

153 R. P. Brinkhuis, F. P. Rutjes and J. C. van Hest, Polym. Chem., 2011, 2, 1449-1462.

154 M. Massignani, H. Lomas and G. Battaglia, Polymersomes: A Synthetic Biological Approach to Encapsulation and Delivery, 2010, pp. 1-40.

155 D. E. Discher and F. Ahmed, Annu. Rev. Biomed. Eng., 2006, 8, 323-341.

156 W. Meier, C. Nardin and M. Winterhalter, Angew. Chem., Int. Ed., 2000, 39, 4599-4602.

157 O. Onaca, M. Nallani, S. Ihle, A. Schenk and U. Schwaneberg, Biotechnol. J., 2006, 1, 795-805.
158 V. Malinova, S. Belegrinou, D. de Bruyn Ouboter and W. P. Meier, Organic Electronics, Springer, 2010, pp. 213-258.

159 J. M. Fletcher, R. L. Harniman, F. R. H. Barnes, A. L. Boyle, A. Collins, J. Mantell, T. H. Sharp, M. Antognozzi, P. J. Booth, N. Linden, M. J. Miles, R. B. Sessions, P. Verkade and D. N. Woolfson, Science, 2013, 340, 595-599.

160 H. Gradišar, S. Božič, T. Doles, D. Vengust, I. HafnerBratkovič, A. Mertelj, B. Webb, A. Šali, S. Klavžar and R. Jerala, Nat. Chem. Biol., 2013, 9, 362-366.

161 Y.-T. Lai, E. Reading, G. L. Hura, K.-L. Tsai, A. Laganowsky, F. J. Asturias, J. A. Tainer, C. V. Robinson and T. O. Yeates, Nat. Chem., 2014, 1065-1071. 